\title{
PREFERENSI PETANI TERHADAP KLON KENTANG BALITSA BAHAN BAKU OLAHAN FRENCH FRIES
}

\section{Farmers' preference on IVegRI potato clones as the french fries processed raw material}

\author{
Asma Sembiring ${ }^{1}$, dan Witono Adiyoga ${ }^{1}$ \\ ${ }^{1}$ Balai Penelitian Tanaman Sayuran Lembang Jl. Tangkuban Perahu No.517 Lembang, Bandung Barat 40391 \\ *email koresponden: rangkayoamah@gmail.com
}

Received: 2019. Revised: $19^{\text {th }}$ September 2019. Accepted: $20^{\text {th }}$ April 2020

\begin{abstract}
Abstrak
Tujuan penelitian ini adalah mengetahui preferensi petani Purbalingga terhadap klon kentang bahan baku olahan french fries Balai Penelitian Tanaman Sayuran (Balitsa) Lembang. Penelitian dilakukan di Kecamatan Karangreja, Kabupaten Purbalingga Jawa Tengah pada bulan Juni hingga Desember 2018. Metode penelitian yang digunakan adalah gabungan antara demplot klon kentang baku olahan french fries serta penelitian partisipatif petani. Tujuh klon kentang bahan baku olahan french fries Balitsa dan tiga pembandingnya ditanam di lapangan. Demplot ini kemudian diobservasi oleh 30 petani kentang pada saat panen. Responden diminta untuk menjawab kuisoner terstruktur. Hasil penelitian menunjukkan bahwa berdasarkan produksi hasil, jumlah mata tunas, kedalaman mata tunas, ukuran umbi dan tampilan kentang secara keseluruhan, dari $10 \mathrm{klon} /$ varietas kentang yang ditampilkan, petani menyukai klon kentang 66 Balitsa sebagai pilihan pertama untuk kentang french fries, diikuti oleh kentang Medians sebagai pilihan ke-2 dan Atlantik sebagai pilihan ke-3.
\end{abstract}

Kata kunci: French fries, klon kentang,preferensi.

\begin{abstract}
The objective of the study was to identify Purbalingga farmer's preference on IVegRI potato clones as the french fries processed raw material. The study was conducted in Karangreja sub-district, Purbalingga district, Central Java on June to December 2018. The research method used a combination between a demo plot of IVeGRI potato clones for french fries processed raw material and participatory farmer research. Seven IVegRI's potato clones for french fries processed raw material and three potato varieties as the comparator were planted in the field. Then, the demo plot was observed by 30 respondents during a harvest. The respondents were asked to fill the structured questionnaire while observing. The result of study showed that based on production, number of sprouts, the depth of sprout, tuber size and potato performance as the whole, from 10 clones/potato varieties that were displayed, the farmers preferred to the IVegRI clone 66 as the first choice, following by Medians as the second choice and Atlantik for the third.
\end{abstract}

Keywords: French fries, potato clones, preference 


\section{PENDAHULUAN}

Industri kentang olahan di Indonesia dalam tahuntahun terakhir menunjukkan perkembangan positif sejalan dengan semakin meningkatnya permintaan bahan baku kentang olahan (Asgar, Kusmana, Rahayu, \& Sofiari, 2011). Selama ini pemain besar dalam industri kentang olahan french fries di Indonesia dikuasai oleh satu perusahaan besar, yang menggunakan bahan baku kentang Atlantik impor sebagai bahan bakunya. Perusahaan yang sama juga sekaligus menguasai hak impor dan distribusi benih Atlantik, serta menjadi pembeli tunggal hasil panen kentang yang ditanam oleh petani dengan mekanisme kontrak yang mereka kembangkan (Adiyoga, Musaddad, \& Sembiring, 2016). Sementara petani mengalami kesulitan dalam mendapatkan benih kentang Atlantik (Kusmana, 2012).

Kentang Atlantik sangat cocok dibuat untuk bahan baku french fries. Namun ketersediaannya terbatas karena menjadi hak tunggal 1 perusahaan. Selain itu, petani kentang kurang menyukai varietas Atlantik karena rentan terhadap penyakit penyakit hawar daun (Phytophthora infestans) (Ambarawati \& Kusmana, 2018) dan layu bakteri (Ralstonia solanacearum) dan hasilnya lebih rendah dibandingkan dengan kentang Granola yang sudah umum ditanam oleh petani (Kusmana \& Basuki, 2004).

Untuk mendukung pemenuhan bahan baku kentang olahan french fries yang permintaannya berpotensi meningkat ditahun-tahun mendatang, Balai Penelitian Tanaman Sayuran (Balitsa) berupaya mengembangan klon-klon kentang lokal french fries sehingga para pelaku dibidang industri ini memiliki alternatif yang lebih banyak dalam memilih jenis varietas kentang sebagai bahan baku. Hingga saat ini, Balitsa telah menghasilkan beberapa klon kentang varietas unggul baru (VUB) yang potensial sebagai bahan baku olahan french fries.
Klon-klon kentang olahan VUB Balitsa perlu didiseminasikan (diperkenalkan) kepada petani untuk mengetahui preferensi petani terhadap klon kentang olahan french fries tersebut. Dengan mengetahui preferensi petani terhadap klon VUB kentang olahan french fries tersebut, ke depannya dapat diketahui klon-klon kentang olahan VUB Balitsa yang potensial untuk dikembangkan dan diproduksi secara besar-besaran guna mendukung industri kentang french fries dengan dukungan suplai bahan baku dari petani.

Kentang Granola masih menjadi menjadi primadona dan varietas yang paling umum ditanam oleh petani Indonesia (Adiyoga, Suwandi, \& Kartasih, 2014; Asgar, 2013). Bagi petani kentang, produktifitas tinggi, ketahanan terhadap penyakit busuk daun dan layu bakteri, umur panen, jumlah mata tunas, kedalaman mata dan ukuran umbi menjadi beberapa faktor yang dipertimbangkan ketika menanam kentang-kentang varietas/jenis baru (Kurniawan \& Suganda, 2014; Adiyoga, Suwandi, \& Kartasih, 2014).

Pengetahuan petani mengenai kentang bahan baku olahan french fries terbilang terbatas, mengingat umumnya petani menanam kentang Granola yang biasa disebut juga dengan kentang sayur. Beberapa petani juga menanam kentang Atlantik, namun hasilnya dijual kembali ke perusahaan yang sekaligus bertindak sebagai penyuplai benih kentang Atlantik kepada petani.

Selama ini, informasi mengenai petani yang memproduksi kentang bahan baku olahan french fries sangat minim/belum ada. Selain itu, pemahaman petani kentang terhadap perbedaan kentang bahan baku olahan french fries dan kentang sayur yang biasa mereka tanam belum didapatkan. Ditambah lagi dengan parameter kualitas french fries pada klon-klon VUB bahan baku olahan french fries belum tampak/didefinisikan dengan jelas. Sehingga, preferensi petani terhadap klon kentang VUB bahan baku olahan french fries dilakukan menggunakan parameter agronomi yang biasa 
dilakukan pada penelitian-penelitian sebelumnya, seperti potensi hasil, ketahanan terhadap penyakit busuk daun, layu bakteri, dan jumlah mata tunas (Ruswandi, 2018; Adiyoga, Suwandi, \& Kartasih, 2014).

Tujuan penelitian ini adalah untuk mengetahui preferensi petani Purbalingga terhadap kentang bahan baku olahan french fries. Diharapkan dari 7 klon VUB Balitsa bahan baku olahan french fries diperoleh 1 hingga 2 klon yang disukai petani. Sehingga pada saat klon VUB kentang Balitsa ini dilepas, varietas kentang bahan baku olahan french fries ini berpotensi besar untuk diadopsi petani secara luas dan berdampak terhadap peningkatan pendapatan petani. Untuk Balitsa sendiri, informasi yang didapatkan dapat digunakan untuk terusmenerus memperbaiki kualitas kentang yang dihasilkan oleh Balitsa ke depannya.

\section{METODE PENELITIAN}

\section{Kerangka Pemikiran}

Diseminasi penelitian pertanian berguna untuk mendorong penyebaran hasil-hasil penelitian pertanian kepada para penggunanya. Saat ini, diseminasi menjadi aktivitas yang tidak terpisahkan dari kegiatan penelitian. Penggunaan media dan komunikasi yang tepat dalam diseminasi hasil-hasil pertanian akan meningkatkan adopsi petani terhadap teknologi maupun varietas baru sayuran yang didiseminasikan (Indraningsih, 2017; Rahmawati, Saleh, Hubeis, \& Purnaningsih, 2017). Hasil-hasil penelitian sayuran akan memberikan kontribusi yang besar bagi petani jika komponen teknologi/varietas sayuran yang dihasilkan oleh lembaga pemerintah seperti Balai Penelitian Tanaman Sayuran (Balitsa) diadopsi dan diterapkan oleh petani.

Dalam mendiseminasikan hasil inovasi penelitian sayuran dapat digunakan berbagai media, antara lain demplot, temu lapang dan pameran (Indraningsih, 2017; Amali, 2015). Penelitian ini menggunakan diseminasi dalam bentuk demplot. Responden petani langsung ke lapangan saat panen kanteng berlangsung. Setelah itu, responden diminta untuk melakukan evaluasi terhadap hasil panen kentang berdasarkan karakteristik yang ditanyakan.

\section{Pengumpulan Data}

Penelitian dilakukan di Kecamatan Karangreja, Kabupaten Purbalingga Jawa Tengah pada bulan Juni hingga Desember 2018. Data yang digunakan adalah data primer dan sekunder. Data primer berasal dari gabungan data demplot di lapangan dan hasil penelitian partisipatif ditingkat petani. Demplot dilakukan dengan menanam 7 klon VUB kentang Balitsa dan 3 kentang pembanding. Ketujuh klon kentang tersebut adalah klon 175, 5, 34, 171, 193, 66 dan klon 1. Sementara pembandingnya kentang Medians, Granola dan Atlantik

Penelitian partisipatif petani dilakukan melalui survei kepada 30 responden petani kentang. Pemilihan responden dilakukan secara purposive (sengaja). Responden yang dipilih adalah petani yang telah menanam kentang minimal satu tahun terakhir. Para petani diminta untuk melakukan evaluasi pada saat panen. Responden petani diminta untuk menjawab pertanyaan dalam bentuk kuisoner, yang meliputi (1) karakteristik sosial ekonomi petani (2) evaluasi dan preferensi petani terhadap karakteristik klon VUB kentang bahan baku french fries pada saat kentang dipanen.

Pada saat panen, petani diminta untuk memilih 3 klon kentang bahan baku olahan yang disukai berdasarkan 5 karakter utama yaitu daya hasil (produktivitas hasil), umur panen, jumlah mata tunas, kedalaman mata dan ukuran umbi. Sementara itu, data sekunder berasal dari hasil-hasil penelitian sebelumnya.

\section{Analisis Data}

Analisis data untuk mengetahui preferensi petani terhadap klon kentang bahan baku olahan french fries menggunakan skoring. Klon/Varietas yang karakternya menjadi pilihan pertama diberi skor 3, pilihan 2 diberi skor 2, pilihan ke-3 diberi skor 1 (Basuki, 2009). Keseluruhan skor karakter kemudian dijumlahkan. Skor total karakter pada klon/varietas 
kentang tertinggi menunjukkan klon/varietas yang paling disukai oleh petani.

\section{HASIL DAN PEMBAHASAN}

\section{Karakteristik Sosial Ekonomi Petani}

Umumnya pendidikan responden adalah SMP (40,7\%), diikuti dengan SD (33,3\%). Rata-rata responden telah menanam kentang kurang lebih 10,3 tahun. Rerata luas lahan kentang yang ditanami responden selama setahun terakhir adalah 1,1 hektar, dengan luasan terbesar mencapai 2 hektar dan luasan terkecil sebesar 0,25 hektar.

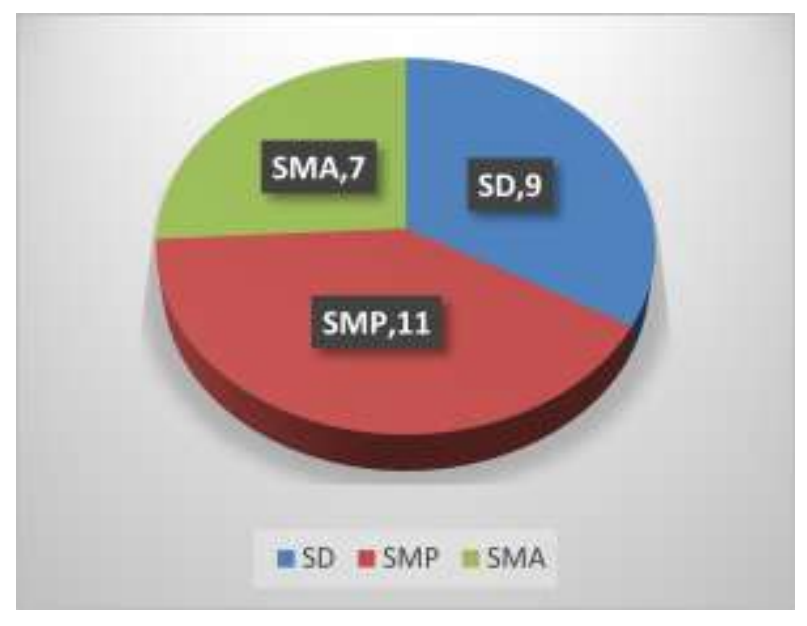

Sumber : Data primer, diolah (2018)

Gambar 1. Tingkat pendidikan responden $(\mathrm{n}=$ 30)

Terdapat $10 \mathrm{klon} / \mathrm{varietas}$ kentang yang ditampilkan kepada petani untuk dipilih varietas yang mana yang paling disukai sebagai bahan baku kentang olahan french fries. Kesepuluh klon/varietas kentang tersebut sebagai mana tertera pada Tabel 1 .

Tabel 1. Klon/varietas kentang untuk survei preferensi petani

\begin{tabular}{ll}
\hline No & klon varietas/varietas \\
\hline 1 & Klon 175 \\
2 & Klon 5 \\
3 & Klon 34 \\
4 & Klon 171 \\
5 & Klon 193 \\
6 & Klon 66 \\
7 & Klon 1 \\
8 & Medians \\
9 & Granola \\
10 & Atlantik \\
\hline
\end{tabular}

Preferensi Petani Terhadap Klon/Varietas Unggul Balitsa Untuk Bahan Baku French fries

Berdasarkan atribut daya hasil (produksi), responden memilih klon 66 sebagai pilihan pertama dengan skor 56, kedua Atlantik dengan skor 46 dan ketiga Medians dengan skor 41. Untuk jumlah mata tunas, petani menyukai klon 66 dengan skor 48, diikuti dengan Medians dengan skor 35 serta ketiga klon 1 dan Atlantik dengan skor masing-masing 28. Penelitian-penelitian sebelumnya menunjukkan bahwa produksi hasil tinggi menjadi faktor yang paling penting bagi petani dalam menggunakan varietas kentang, terutama dalam pembelian benih (Gunadi, Karjadi, \& Sirajuddin, 2014; Wicaksana, Muhaimin, \& Koestiono, 2013).

Dari segi kedalaman mata tunas, petani menyukai kentang klon 66 dengan skor 45, dilanjutkan dengan Medians dengan skor 42 dan Atlantik dengan skor 29. Untuk ukuran umbi, pilihan pertama petani jatuh

Tabel 2. Skor pilihan responden untuk 3 klon/varietas kentang terpilih berdasarkan preferensi petani

\begin{tabular}{llll}
\hline Atribut & Klon 66 & Median & Atlantik \\
\hline Produksi & 56 & 41 & 46 \\
Jumlah mata tunas & 48 & 35 & 28 \\
Kedalaman mata tunas & 45 & 42 & 29 \\
Ukuran umbi & 59 & 41 & 27 \\
Tampilan umbi keseluruhan & 61 & 46 & 30 \\
\hline
\end{tabular}

Sumber : Data primer, diolah (2018) 
pada klon 66 dengan skor 59, pilihan kedua pada Medians dengan skor 41 dan ketiga adalah Atlantik dengan skor 27. Untuk tampilan keseluruhan kentang, petani memilih klon/varietas yang paling disukai adalah klon 66 dengan skor 61, kedua Medians dengan skor 46 dan ketiga Atlantik dengan skor 30 (Tabel 2).

Untuk klon 66, pilihan pertama petani, dari segi produksi (hasil panen), responden yang memilih sebagai pilihan pertama sebanyak 43,3\%, pilihan kedua $16,7 \%$ dan ketiga $23,3 \%$. Untuk jumlah mata tunas, responden yang memilih sebagai pilihan adalah $40 \%$, kedua $30 \%$ dan ketiga adalah $16,7 \%$.

Sementara itu, berdasarkan tampilan kentang secara keseluruhan, jumlah petani yang memilih klon 66 sebagai pilihan pertama 50\%, kedua $16,7 \%$ dan ketiga 20\%. (Tabel 3).

Petani memilih klon 66 sebagai pilihan pertama karena produksi panennya lebih tinggi (berdasarkan pengamatan visual di lapangan), ukuran umbi besar (Handayani, Kusmana, \& Kurniawan, 2018), mata tunas dangkal dan sedikit sehingga bila dikupas yang akan terbuang sedikit dan lebih efisien, bentuk umbi

Tabel 3. Jumlah responden pemilih klon 66 berdasarkan karakter yang dievaluasi

\begin{tabular}{|c|c|c|c|c|c|c|c|c|}
\hline \multirow{2}{*}{$\begin{array}{l}\text { Karakter } \\
\text { diukur }\end{array}$} & \multicolumn{6}{|c|}{ Jumlah responden yang memilih } & \multirow{2}{*}{$\begin{array}{c}\text { Total } \\
\text { responden }\end{array}$} & \multirow[t]{2}{*}{$\%$} \\
\hline & Pilihan 1 & $\%$ & Pilihan 2 & $\%$ & Pilihan 3 & $\%$ & & \\
\hline Produksi & 13 & 43,30 & 5 & 16,70 & 7 & 23,30 & 25 & 83,30 \\
\hline Jumlah mata tunas & 10 & 33,30 & 7 & 23,30 & 4 & 13,40 & 21 & 70,00 \\
\hline $\begin{array}{l}\text { Kedalaman mata } \\
\text { tunas }\end{array}$ & 9 & 30,00 & 7 & 23,30 & 4 & 13,40 & 20 & 66,70 \\
\hline Ukuran umbi & 12 & 40,00 & 9 & 30,00 & 5 & 16,70 & 26 & 86,70 \\
\hline $\begin{array}{l}\text { Tampilan } \\
\text { keseluruhan }\end{array}$ & 15 & 50,00 & 5 & 16,70 & 6 & 20,00 & 26 & 86,70 \\
\hline
\end{tabular}

Sumber : Data primer, diolah (2018)

pertama adalah $33,3 \%$, pilihan kedua $23,3 \%$ dan pilihan ketiga 13,4\% (Tabel 3).

Berdasarkan kedalaman mata tunas, responden yang memilih klon 66 sebagai pilihan pertama adalah $30 \%$, kedua $23,3 \%$ dan $13,4 \%$. Untuk ukuran umbi, responden yang memilih sebagai pilihan pertama lebih panjang dan harganya lebih mahal karena lebih disukai oleh pedagang. Petani berpendapat klon 66 sangat cocok dijadikan sebagai bahan baku olahan french fries. Untuk hasil panen yang lebih tinggi menurut petani, keterangan ini kemudian dikonfirmasikan dengan hasil panen demplot ril di lapangan. Hasil konfirmasi menunjukkan,

Tabel 4.Preferensi petani terhadap klon/varietas kentang pada saat panen berdasarkan tampilan kentang secara keseluruhan

\begin{tabular}{|c|c|c|c|c|c|}
\hline \multirow{2}{*}{$\begin{array}{l}\text { Klon/varietas } \\
\text { kentang }\end{array}$} & \multicolumn{5}{|c|}{ Preferensi petani saat panen $(n=30)$} \\
\hline & $\begin{array}{l}\text { Pilihan ke } 1 \text {, } \\
\text { jumlah petani }\end{array}$ & $\begin{array}{l}\text { Pilihan ke 2, } \\
\text { jumlah petani }\end{array}$ & $\begin{array}{l}\text { Pilihan ke } 3 \text {, } \\
\text { jumlah petani }\end{array}$ & $\begin{array}{l}\text { Total petani } \\
(\%)\end{array}$ & $\begin{array}{l}\text { Total skor } \\
\text { preferensi }\end{array}$ \\
\hline Klon 175 & 0 & 2 & 0 & 6,70 & 4 \\
\hline Klon 5 & 0 & 0 & 1 & 3,30 & 1 \\
\hline Klon 34 & 0 & 0 & 0 & 0,00 & 0 \\
\hline Klon 171 & 0 & 2 & 4 & 20,00 & 8 \\
\hline Klon 193 & 0 & 2 & 3 & 16,70 & 7 \\
\hline Klon 1 & 0 & 5 & 5 & 33,30 & 15 \\
\hline Medians & 10 & 5 & 6 & 70,00 & 46 \\
\hline Granola & 1 & 1 & 2 & 16,70 & 7 \\
\hline Atlantik & 4 & 8 & 2 & 46,70 & 30 \\
\hline
\end{tabular}

Sumber : Data primer, diolah (2018) 
klon/varietas dengan produksi tertinggi yang ditanam di Purbalingga untuk luasan per plot $8 \mathrm{~m}^{2}$ adalah Atlantik dengan produksi $36,8 \mathrm{~kg}$, diikuti dengan Medians dengan hasil 32,8 $\mathrm{kg}$ dan klon 66 sebesar $26,5 \mathrm{~kg} /$ per plot (Kusmana, 2018).

Penelitian terpisah yang dilakukan oleh Kusandriani (2014) menunjukkan bahwa kentang Medians juga merupakan kentang yang cocok untuk bahan baku olahan industri yang tak kalah dengan Atlantik dan memiliki potensi daya hasil tinggi, dengan hasil diatas 24 ton per hektar.

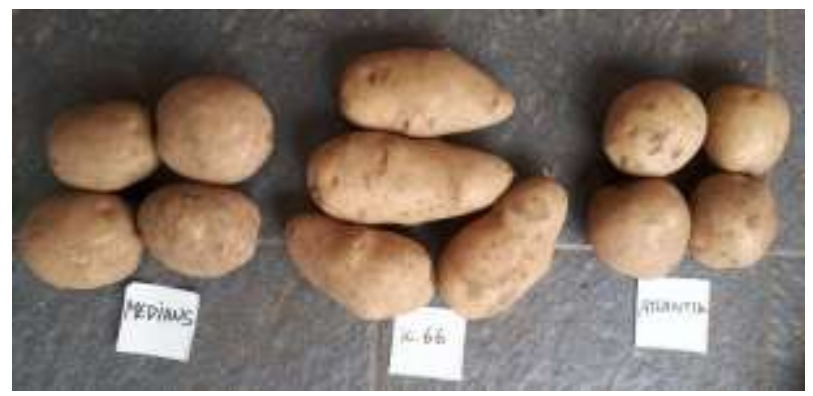

Sumber : Data primer, diolah (2018)

Gambar 2. Tampilan kentang Medians, klon 66 dan Atlantik

Untuk Medians sebagai pilihan kentang olahan french fries kedua terbaik, responden yang menjadikannya sebagai pilihan pertama berjumlah 10 orang, pilihan ke-2 sebanyak 5 orang dan pilihan ke3 sebanyak 6 orang. Total yang memilih Medians sebagai bahan baku olahan kedua terbaik adalah $70 \%$ dari responden (Tabel 4).

Akan halnya untuk kentang Atlantik, responden yang memilih sebagai pilihan pertama 4 orang, pilihan ke2 sebanyak 8 orang dan pilihan ke-3 sebanyak 2 orang. Total yang memilih Atlantik sebagai bahan baku olahan ketiga terbaik adalah $46,7 \%$ dari keseluruhan responden (Tabel 4).

\section{KESIMPULAN}

\section{Kesimpulan}

Hasil demplot klon/varietas kentang Balitsa di Purbalingga menunjukkan, dari $10 \mathrm{klon} /$ varietas kentang yang ditampilkan, petani menyukai klon kentang 66 Balitsa sebagai pilihan pertama untuk kentang french fries, diikuti oleh kentang Medians dan Atlantik. Sehingga, klon kentang 66 dan varietas kentang Medians Balitsa berpeluang besar untuk dijadikan bahan baku olahan french fries.

\section{Saran}

Sebagai saran, Pemulia kentang diharapkan mampu meningkatkan potensi produksi klon kentang 66 mengingat dari preferensi petani, klon kentang ini menjadi pilihan kentang pertama yang disukai sebagai bahan baku olahan french fries. Meskipun dari atribut jumlah mata tunas, kedalaman mata tunas, ukuran umbi dan tampilan umbi secara keseluruhan klon 66 lebih disukai petani, namun bila produksinya lebih rendah dari klon/varietas yang lainnya, maka petani dapat mengalihkan kesukaannya kepada kentang lain yang memiliki produksi lebih tinggi seperti Medians dan Atlantik.

\section{UCAPAN TERIMA KASIH}

Terima kasih kepada Pak Nana Sujana yang telah membantu dalam pelaksanaan kegiatan survei lapangan.

\section{Daftar Pustaka}

Adiyoga, W., Musaddad, D., Sembiring, A. (2016). Studi sosial ekonomi rantai pasok kentang untuk bahan olahan di Jawa Barat. Bandung: Balai Penelitian Tanaman Sayuran Lembang, Bandung.

Adiyoga, W., Suwandi, \& Kartasih, A. (2014). Sikap Petani Terhadap Pilihan Atribut Benih dan Varietas Kentang ( Farmers ' Attitude Towards Attribute Choices of Potato Seed and Variety ). J. Hort, 24(1), 76-84.

Amali, N. (2015). Diseminasi teknologi cabai merah melalui demplot GAP. In M. Yasin, A. Noor, Suryana, E. S. Rohaeni, \& Agus Hasbianto (Eds.), Prosiding Seminar Nasional Inovasi Teknologi Pertanian 
Spesifik Lokasi, Banjarbaru 6-7 Agustus 2014. Kalimantan Selatan: BPTP Kalimantan Selatan.

Asgar, A. ((2013)). Kualitas umbi beberapa klon kentang ( Solanum tuberosum L .) dataran medium untuk keripik * [ Tuber Quality of some Potato ( Solanum tuberosum L .) Clones of Medium Altitude Area for Chips Making ]. . Berita Biologi, 29-37.

Asgar, A., Rahayu, S. T., Kusmana, \& Sofiari, E. (2011). Uji Kualitas Umbi Beberapa Klon Kentang untuk Keripik. J. Hort, 21(1), 51-59.

Dinar, A., Uji, A., \& Kentang, A. K. (2018). Uji Adaptasi Klon-Klon Kentang Transgenik Tahan Hawar Daun Pada Agroekosistem Jawa Barat dan Jawa Tengah ( Adaptation Test of Transgenic Potato Resistance to Late Blight Under Agro Ecosystem of West and Central Java. J. Hort, 28(2), 175-182.

Gunadi, N., Karjadi, A., \& Sirajuddin. (2014). Pertumbuhan dan Hasil Beberapa Klon Kentang Unggul Asal International Potato Center di Dataran Tinggi Malino, Sulawesi Selatan. J. Hort, 24(2), 102113.

Handayani, T., Kusmana, \& Kurniawan, H. (2018). Respon dan Seleksi Tanaman Kentang Terhadap Kekeringan ( Response and Selection of Potato Plants to Drought ). J. Hort, 28 (2)(517), 163-174.

Indraningsih, K. S. (2017). Strategi Diseminasi Inovasi Pertanian dalam Mendukung Pembangunan Pertanian (Vol. 35(2)). Forum Penelitian Agro Ekonomi.

Kurniawan, H., \& Suganda, T. . (2014). Uji Kualitas Ubi Beberapa Klon Kentang Hasil Persilangan untuk Bahan Baku Keripik. Jurnal Agro, 1(1), 33-43.

Kusmana. (2012). Uji Adaptasi Klon Kentang Hasil Persilangan Varietas Atlantik sebagai Bahan Baku Keripik Kentang di Dataran Tinggi Pangalengan. ,. $J$. Hort, 22(4), 342-348.

Kusmana. (2018). Uji keunggulan dan kebenaran kentang varietas untuk bahan baku olahan french fries. Bandung: Balai Penelitian Tanaman Sayuran Lembang,Bandung.

Kusmana, \& Rofik Sinung Basuki. (2004). Produksi dan Mutu Umbi Klon Kentang dan Kesesuaiannya sebagai Bahan Baku Kentang Gor eng dan Keripik Kentang. $J$. Hort, 14(4), 246-252.

Rahmawati, Saleh, A., Hubeis, M., \& Purnaningsih, N. (2017). Factors Related to use of Communication Media Spectrum Communication Network Dissemination in Multi Channel. International Journal of Sciences IJSBAR, 34(1), 182-192.

Ruswandi, A. (2018). Preferensi Petani Terhadap Varietas Kentang Dayang Sumbi Agrihorti dan Sangkuriang Agrihorti Tahan Terhadap Penyakit Busuk Daun. $C R$ Journal, 4(2), 83-94.

Wicaksana, B. E., Abdul Wahib Muhaimin, \& Djoko Koestiono . (2013). Analisis sikap dan kepuasan petani dalam menggunakan benih kentang bersertifikat (Solanum tuberosum L.) (Kasus di Kecamatan
Bumiaji, Kota Batu). . Habitat Volume, XXIV(3), , 184-193. 